\title{
The determination of short circuits and grounding faults in electric power systems using time-frequency analysis
}

\author{
Vedat Esen \\ Vocational High School, Department of Electricity, İstanbul Arel University, Istanbul, Turkey

\section{Bulent Oral} \\ Department of Electrical \& Electronics Engineering, Faculty of the Technology, Marmara University, Istanbul, \\ Turkey

\section{Tahir Cetin Akinci} \\ Department of Electrical \& Electronics Engineering, Engineering Faculty, Kirklareli University Kirklareli, Turkey
}

\begin{abstract}
In order to ensure that electrical energy reaches consumers uninterrupted, researchers constantly try to improve power transmission lines. To realize this improvement, probable faults should be analysed through every known method, and new methods should also be implemented. In this study, firstly, the Keban power transmission line located in the Eastern Anatolia region of Turkey was modelled. After that, probable short circuit scenarios were applied on the model, and the short circuit faults in the scenarios were analysed by using the Fourier analysis. The Fourier analysis is a mathematical method that is used as an effective way to determine the sudden changes in the frequency and time band. The study was successful in determining phase and grounding faults through the analyses of the scenarios using Fourier analysis. The fact that the mathematical method was applied on the probable scenarios on a physical model increases the importance of the study.
\end{abstract}

Keywords: Fourier analysis, short circuits in electrical power systems, modelling electrical power systems, time-frequency analysis

\section{Introduction}

Today, the production, transmission and distribution of electrical energy are performed firstly by planning the processes through computer programs, evaluating certain risk factors by performing various analyses, performing an economical analysis and lastly by the application of the plans (IAEA, 1995). With the improvements in computer technology, these analyses and mathematical modelling processes have become inevitable. Many factors that previously had to be neglected in the process, from the production of energy to its distribution to end users, can now be calculated and the analysis of those evasive probable shortcomings can be performed in the planning phase (Paska, 2007; Billinton et al., 1997; Chanda and Bhattschsrjee, 1994).

Two of the most important types of faults in electrical power systems to come to mind are short circuits and probable grounding faults. Short circuiting is presently one of the most prevalent faults in electrical power systems (Yuhai et al., 2007). These faults may occur between the phases as well as between the phases and the ground (Hambley, 2011). Short circuits can be classified as three phase short circuit faults, arc faults and grounding faults. The faults may occur for various reasons. These faults can be analysed through conventional methods as well as modern sign processing methods (Akinci et al., 2013). Sign processing methods provide successful results through the analysis of the fault in the frequency domain.

The only valid standard for short circuit studies in the world is IEC 60609 (Kasikci, 2002). Improvements in computer systems provide us with the opportunity to perform modelling processes in 
these studies, and enable us to get results in a much shorter time with highly realistic simulations.

The Matlab-Simulink (C) software, which was used for the simulations in this study, has also been conducted using many similar studies. There are many studies on short circuit faults performed through various simulation techniques in the literature, as well as many other studies where simulation programs were used (Kankaratug et al., 2011; Faig et al., 2010; Pamuk, 2011; Aygen et al., 1995; Gopalakrishnan et al., 2000; Miroshnik, 2000; Maslo and Vnoucek, 2009; Ekici et al., 2009; Serrican et al., 2010; Ekiz and Tumay; Závodný, 2005; Evrenosoglu, 2005; Tekin, 2006).

In recent years, the evaluation of short circuit effects in power systems through the static synchronized serial compensator method (Kankaratug et al., 2011), the evaluation of short circuits in electrical systems which include wind generators (Tekin, 2006), the evaluation of short circuits in the Van city electric power transmission line (Dogruer, 2007), and the computer modelling of the Tedas block substation - stadium distribution system in Adapazarı (Acar, 2008) have been performed. In this study, the Keban power transmission line was modelled and the faults occurring as a result of the probable short circuiting scenarios were analysed by using the Short Time Fourier Transformation. At the end of the analysis, the characteristic properties of phase-ground and phase-phase faults were determined using the Short Time Fourier Transform (STFT) method.

\section{Types of short circuits}

Short circuit currents can be calculated based on the impedance the circuit represents. This impedance, in turn, can be calculated by summing up the various resistances and the reactance in the power source and the error line loop. Mathematically, this short circuit impedance is calculated through $\left(Z_{S C}\right)$ Equation (1). In this calculation, $\Sigma R$ is the sum of the serial resistances and $\Sigma \mathrm{X}$ is the sum of the serial reactance (Schneider Electric, 2005).

$$
Z_{s c}=\sqrt{\left(\sum R\right)^{2}+\left(\sum X\right)^{2}}
$$

The calculation of short circuit currents is based on Ohm's Law. The mathematical expression is given in Equation (2). In this expression, $\mathrm{I}_{\mathrm{SC}}$ is the short circuit current in the three phase short circuit (Schneider Electric, 2005). $V_{n}$ is the uncharged nominal network voltage and $3-5 \%$ higher than the voltage on the terminals.

$$
I_{S C}=\frac{V_{n}}{\sqrt{3} \times Z_{S C}}
$$

Different types of short circuits can be seen in electrical systems. Short circuits can be classified under four titles as three phase short circuits, two phase short circuits, the phase - neutral short circuits and the phase - ground short circuits. Three phase short circuits are symmetric faults since currents of equal amplitudes flow through the phases in these faults. Phase-ground, two phase and two phase-ground short circuits are classified as asymmetrical faults (Smeets and Lathouwers, 2010).

Three phase short circuits are the most common ones in electrical systems. However, it is also the heaviest form of short circuiting, and the electrical systems have to be sized according to the greatest short circuit currents, which are three phase symmetrical short circuit currents, with respect to their endurance. On the other hand, important short circuit accidents are seen in phase - neutral and phase - ground short circuits. It is also possible for there to be a short circuit between the neutral-ground-conductors or two conductors on the same phase.

Three phase short circuit is a symmetrical fault on which the determination of the opening capacity of the current overflow protection device and the establishment of thermal endurance are based (Kasikci, 2002). The short circuit current flowing through the given circuit was defined as $\mathrm{I}_{\mathrm{SC} 3}$, and the formula pertaining to the short circuit current was given in Equation (3).

$$
I_{S C 3}=\frac{V_{L L}}{\sqrt{3} \times \mathrm{Z}_{S C}}
$$

In Eq. (3), I $\mathrm{SC}_{\mathrm{SC}}$ represents the three phase short circuit current, $V_{\mathrm{LL}}$ represents the voltage between the phases and $Z_{S C}$ represents the impedance.

In this type of short circuiting, the fault occurs between the two phases providing the voltage between phases $\left(\mathrm{V}_{\mathrm{LL}}\right)$. The short circuit current $\left(\mathrm{I}_{\mathrm{SC} 2}\right)$ in a two phase short circuit fault is lower than that of a three phase fault (Short Circuits Analysis, 2013). The formula for the calculation of the two phase short circuit current is given in Eq (4).

$$
I_{S C 2}=\frac{V_{L L}}{2 \times Z_{S C}}=\frac{\sqrt{3} I_{S C 3}}{2}=0.86 I_{S C 3}
$$

The phase-neutral short circuit is a fault caused by the contact between the phase and the neutral (Short Circuits Analysis, 2013). The model for phase-neutral short circuits is and the formula, with the short circuit current on this line defined as $\mathrm{I}_{\mathrm{SC} 1}$, was given in Eq. (5).

$$
I_{S C I}=\frac{V_{l . t .}}{\sqrt{3} \times\left(Z_{S C}+Z_{L, n}\right)}
$$


In some special cases of the phase-neutral faults, the zero component impedance of the source is lower than $Z_{\mathrm{SC}}$. This can be seen in the star-cross connected transformers or the secondary generators (operating in power outages). Therefore, the short circuit current in a phaseneutral short circuit can be greater than that of a three phase fault (Short Circuits Analysis, 2013).

In a phase-ground short circuit, a component impedance of zero occurs in motion. The short circuit current in a phase-ground fault is expressed as $\mathrm{I}_{\mathrm{SCO}}$ and its mathematical expression is given in Eq. (6).

$$
I_{S C 0}=\frac{V_{t . t .}}{\sqrt{3} \times\left(Z_{S C}+Z_{0}\right)}
$$

\section{Modelling the Keban transmission line and the simulation of short circuiting}

Modelling or simulation are the terms used in the systematic evaluation and design of an existing system. Mathematical modelling is an efficient and economical way of better understanding, analysing and designing systems (Unal, 1996).

In modelling, the model should be mathematically calculable and detailed enough to allow for the same results obtained from the real system, and the results should reflect the reality. In a study about the performance of a system, first, a model of the system should be constructed. A model should be similar to a real system; it should be a simplified example of the ideal state of a system. The modelling of electrical systems is especially important, since it allows for future faults to be predicted and calculated and the precautions to be taken (Patel et al., 2002).

In this context, the model used in this study was designed as an exact model of the Keban line using 2009 TEIAS data for the parameters on the transmission line under ideal conditions.

Transmission systems are the systems which encompass everything between the production plants and the distribution systems, and in which the transmission of electrical energy at the levels of High Voltage (HV) and Very High Voltage (VHV) are performed. In Turkey, the transmission system voltage level is standardized as $380 \mathrm{kV}$ and $154 \mathrm{kV}$ (TEIAS, 2011).

The length of the $380 \mathrm{kV}$ lines in Turkey is approximately $14420 \mathrm{~km}$ and their carrying capacity is approximately $1000 \mathrm{MW}$. Even though relay stations are sufficient, transmission system insufficiency and problems persist in certain areas. As a result of the new dams built in Turkey in order to meet the energy need and the disruptions in the power transmission lines after the 1999 Marmara earthquake, after 2006, the transmission lines in the country are constantly being renewed through the new budget and new programs implemented, and they are improved with new lines, new transformer groups, or adding new thermal plants to the networks. These improvements and renewals constantly cause changes in power transmission and distribution lines. According to data from TEIAS, the production capacity of present plants in 2010 was $222,533 \mathrm{GWh}$, while this number is expected to be 255,362 GWh in 2012 when the new plants which already had their licenses and began construction start to operate. Additionally, a $4000 \mathrm{MW}$ additional consumption need every year necessitates the present system to be altered every year and new plants to be added to the system. This renewal and improvement continue without any interruption with the added effect of industrialization and urbanization.

In this study, the $380 \mathrm{kV}$ Keban power transmission line was realistically modelled using the 2009 TEIAS data. The modelling was performed using the Matlab-Simulink (C) software. Keban Transmission Line Matlab Simulink Modelling is shown in Figure 1.

\section{Modelling with system parameters}

The load distribution of power systems in Turkey is done and controlled by the National Dispatching Centre. These institutions are responsible for the maintenance, work and load distribution of the interconnected system elements in their regions (TEIAS; EMO, 2007; Donmez, 2008). The map showing Dispatching Centre regions is given in Figure 2 (TEIS).

In the load dispatching map given in Figure 2, regions can be seen to have integrations with the neighbouring countries besides the integrations among them. In this study, the South-eastern Anatolia Power system in the Electrical Power Network of Turkey was evaluated, and the 380 $\mathrm{kV} / 1,530$ MVA Keban transmission line was modelled. The data from the Turkey Electric Transmission Corporation (Donmez, 2008) was used in the model. The load values and other parameters of the selected line reflect the properties of the interconnected network, which was updated in 2009. The line schematics of the model are shown in Figure 3.

In Figure 3, the model of the line on the Keban transmission line was constructed. The schematics of the faults are given in Figure 4. Here, the point (1) identifies the first data collection point, and (2) denominates the second. The second point is also the point of fault where short circuiting occurs.

In Figure 4, the data collection system pertaining to the Keban power transmission line is shown schematically. The explanations of the scenarios on the model are given in Table 1. 


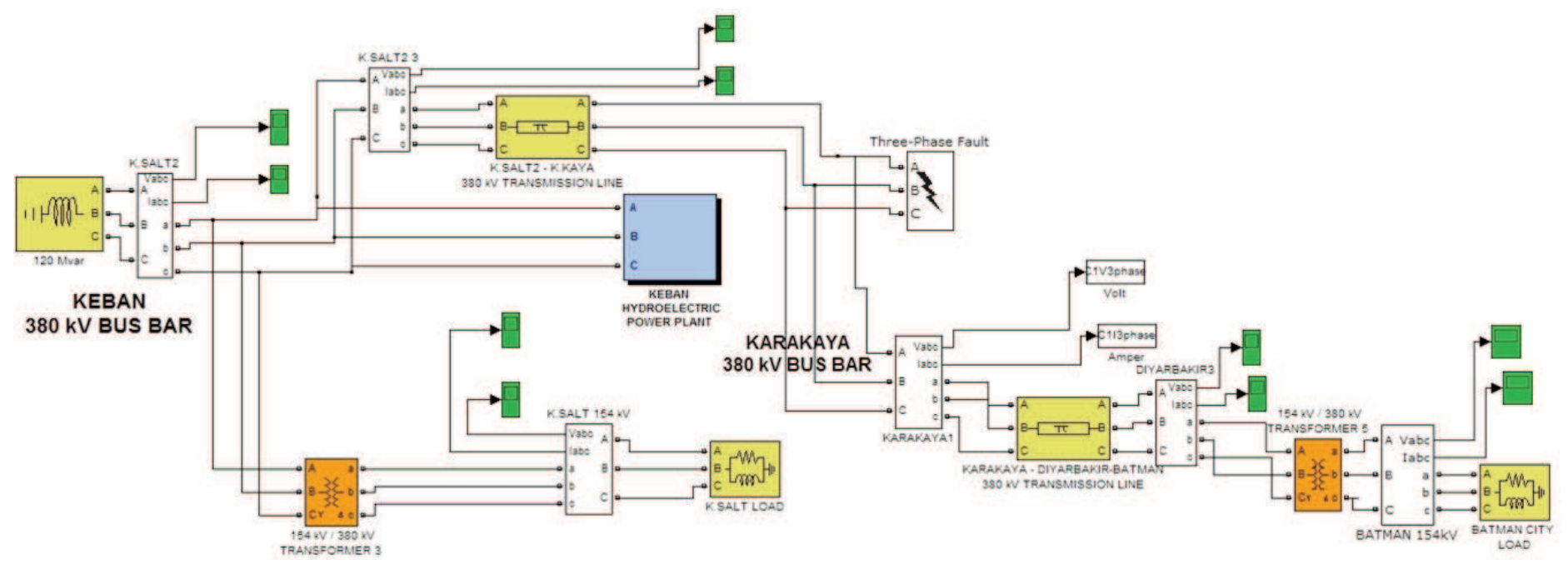

Figure 1: Keban transmission line Matlab Simulink modelling (TEIAS)

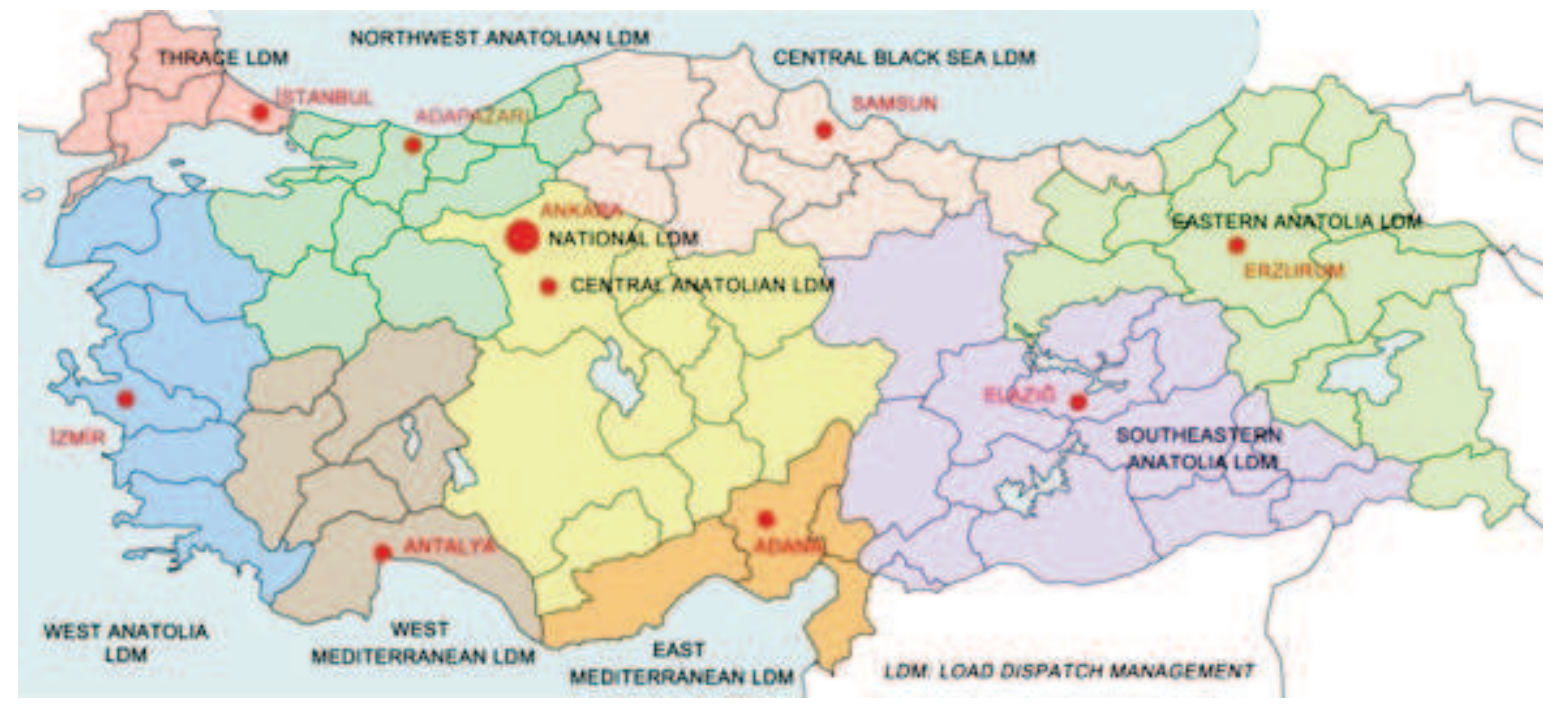

Figure 2: Inter-regional integration plan on the Turkey electrical network (TEIAS)

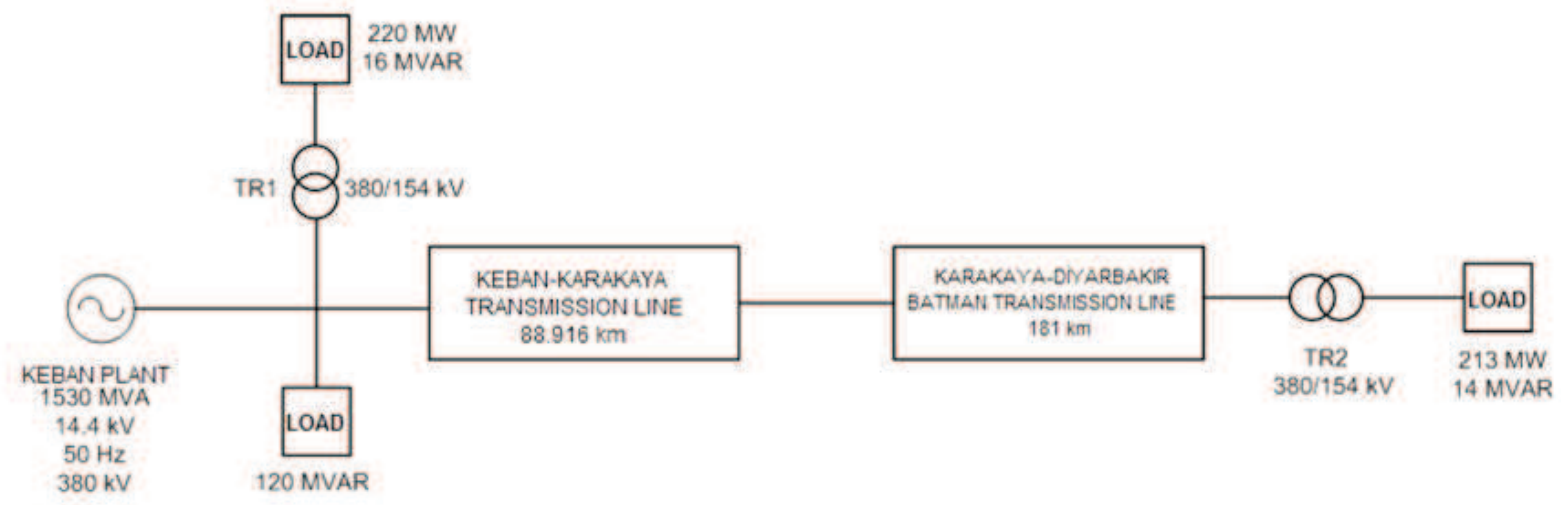

Figure 3: Keban power transmission line plan 


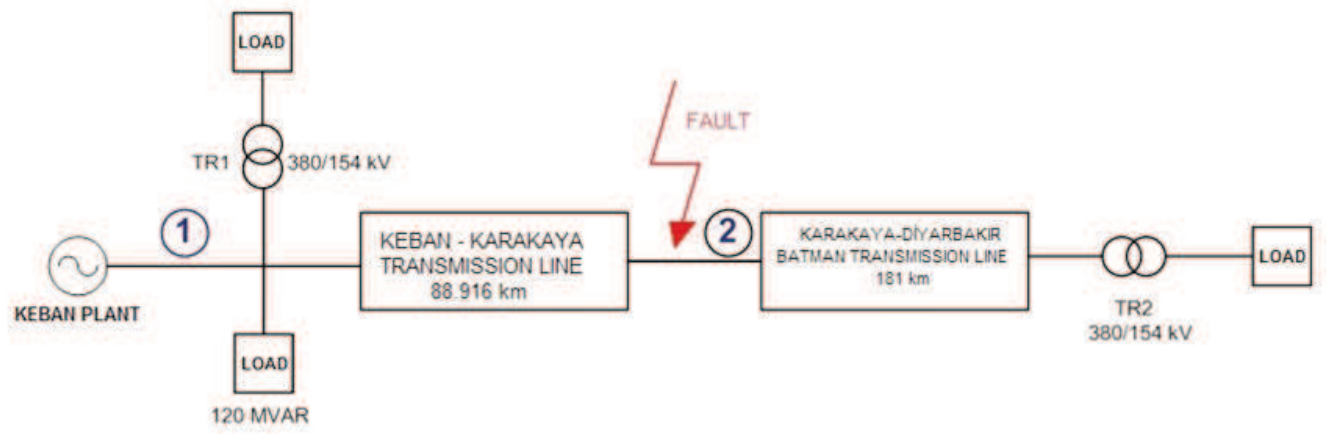

Figure 4: Keban power transmission line data collection plan

Table 1: Short circuit scenarios are created on the model

\begin{tabular}{ll}
\hline Case 1 & $\mathrm{R}$ Phase - Ground Short Circuit \\
\hline Case 2 & $\mathrm{R}-\mathrm{S}$ Phase - Ground Short Circuit \\
\hline Case 3 & $\mathrm{R}-\mathrm{S}-\mathrm{T}$ Phase - Ground Short Circuit \\
\hline Case 4 & $\mathrm{R}-\mathrm{S}$ Phase Short Circuit (Two Phase ) \\
\hline Case 5 & $\mathrm{R}-\mathrm{S}-\mathrm{T}$ Phase Short Circuit (Three Phase) \\
\hline
\end{tabular}

In Table 1, five basic scenarios were taken and the type of fault each scenario represents was
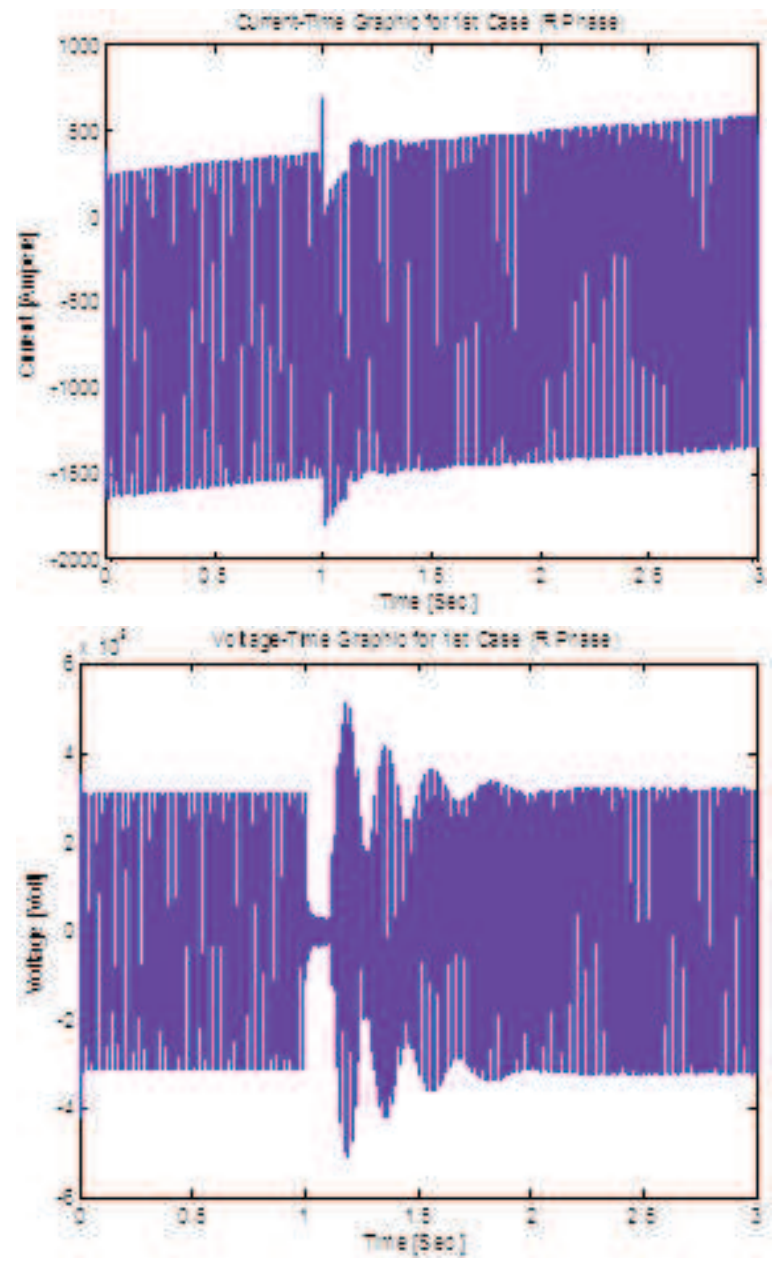

Figure 5: R phase-ground short circuit currenttime and voltage-time graphic shown. These scenarios include Phase-Ground or Phase-Phase short circuits. Figure 5 shows that Matlab Simulink models created faults in Table 1, and the time-frequency analysis method was used for these failures. Figure 5 shows the Current-Time and Voltage-Time graphs for an $\mathrm{R}$ phase-ground fault formed on a point on the line. The timing for the short circuit event starts at the $1^{\text {st }}$ second and continues until the $1.3^{\text {rd }}$ second. The short time short circuit event, the current and the voltage to time graphs are given in Figures 10, 11 and 12, respectively.

The current-time graph of the second case is given in Figure 6. It can be clearly seen here that the second case graphs are different from the graphs of the first fault point. Here, the $1^{\text {st }}$ fault point is closer to the generator point of the Keban plant and at the beginning of the transmission line. The second data collection point ( $2^{\text {nd }}$ point) is on the line between the $89 \mathrm{~km}$ transmission line and the $181 \mathrm{~km}$ transmission lines. The $2^{\text {nd }}$ point is where the fault is simulated to occur. It has also been used in the data collection as a measurement point. This transmission line is shown in Figure 3, and the line schematics are the occurrence point for the faults as shown in Figure 4. Fault scenarios were formed based on the line schematics in Figure 4.

In Figure 7, the $r$ Phase-Ground short circuit (Case 1 ) of the data gathered from the $2^{\text {nd }}$ point is

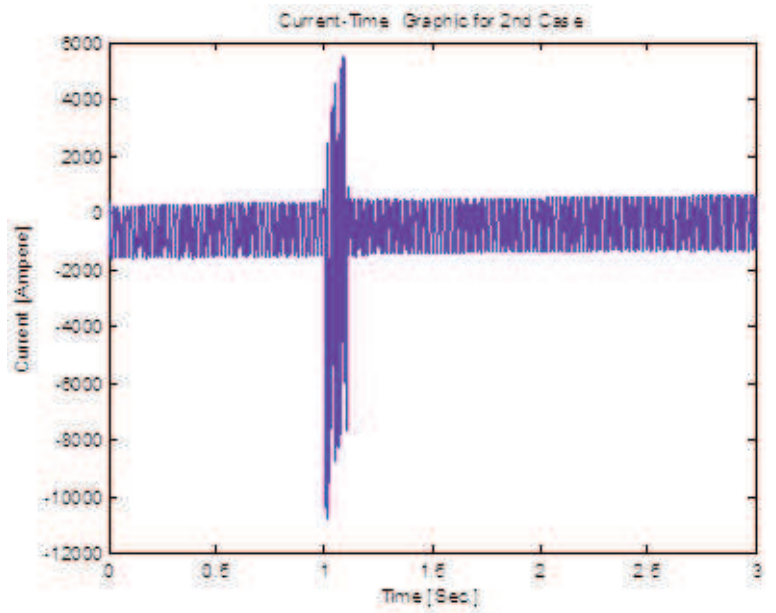

Figure 6: Current-time graphic for Case 2 
given. The graph shows, the formation of an $\mathrm{R}$ phase-ground short circuit after the $1^{\text {st }}$ second can be clearly seen. This graphic is a current-time graphic and very different from the voltage-time graphic. This difference is caused by the $2^{\text {nd }}$ data point located between two transmission lines. Similarly, the voltage-time graphic of the Case 5 is given in Figure 8.

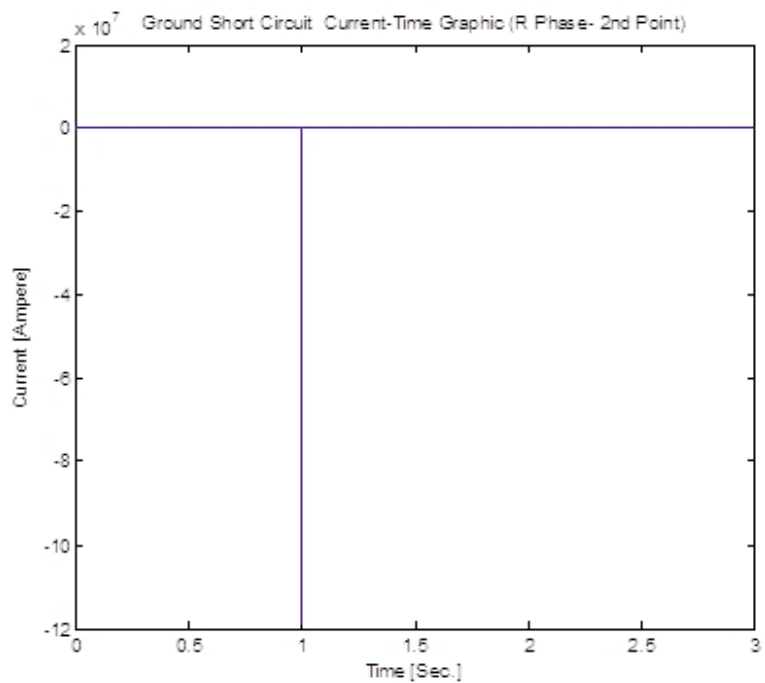

Figure 7: R phase - ground short circuit current-time graphic ( $R$ phase- $2^{\text {nd }}$ point)

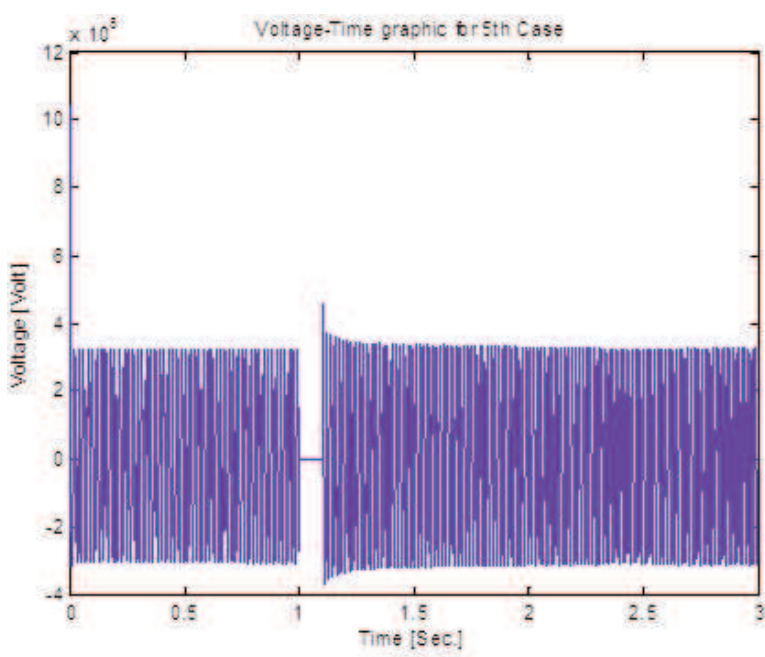

Figure 8: Voltage-time graphic for the Case 5

\section{Mathematical methods}

In this section, the mathematical methods used in the analysis of short circuit events in the electrical power systems are mentioned. The Time-Frequency analysis method was used in the analysis.

\section{The time-frequency analysis method}

Spectral analysis methods (Time-frequency analysis) are Fourier Transformation (FT) based approaches, and this study used mostly the Short Time Fourier Transformation (STFT) approach. The STFT approach is an alternative method based on the classic Fourier Transformation used in the analysis of dynamic data (Vaseghi, 1996; Akinci et al., 2009; Onal and Dikun, 2013).

$$
S_{y y}(f)=\frac{1}{N}|X(m \Delta f) Y(m \Delta f)|
$$

\section{Short time Fourier transformation and the spectrogram}

Let us assume $x(t)$ is a stationary sign to determine STFT. This sign is framed in a fixed $g(t)$ dimension cantered on $\tau$ time. In this case, the STFT is of the sign (Akinci et al., 2009; Onal and Dikun, 2013; Seker and Akinci, 2012).

$$
\begin{aligned}
& \operatorname{STFT}\{x(t)\} \equiv X(\tau, f)=\int_{-\infty}^{+\infty} x(t) g(t- \\
& \tau) \exp [-j 2 \pi f t] d t
\end{aligned}
$$

The equation of the sign can be identified on the time-frequency ( $t, f)$ plane with a two dimensional function. The analysis depends on the chosen window size $g(t)$. After the window $g(t)$ is chosen, the resolution of the STFT is fixed throughout the time-frequency plane. In a disjoint case it is identified with Eq. (9).

$$
\begin{aligned}
& \operatorname{STFT}\{x(n)\} \equiv X(m, f)=\sum_{n=-\infty}^{+\infty} x(n) g(n- \\
& m) e^{-j \omega n}
\end{aligned}
$$

The amplitude changes on the time-frequency plane for the Fourier transformation windowed for the $x(t)$ signal in the time identification region is observed through the equality below:

$$
S\{x(t)\} \equiv|X(\tau, f)|^{2}
$$

In this context, the $S\{$.$\} value is called the spec-$ trogram of the $x(t)$ signal.

\section{The spectral analysis of the short circuit fault}

In this section, the analysis of the data obtained from the Keban energy transmission line model through the short circuit fault was performed with the Fourier method (Time-Frequency analysis). Analyses for every scenario or case were performed in the study.

In Figure 9, as a result of a phase-ground short circuit, high frequency components begin to form after the $1^{\text {st }}$ second. Although the fundamental frequency of the system is $50 \mathrm{~Hz}$, frequencies as high as almost $3 \mathrm{kHz}$ occur.

Figure 10 demonstrates the time frequency analysis output of the current short circuit for the $\mathrm{R}$ phase of Case 2. As seen in the analysis, the high frequency components are only seen at the moment of the short circuit fault, and current flows through the circuit with the system frequency, which is about the fundamental frequency $50 \mathrm{~Hz}$, in other time 


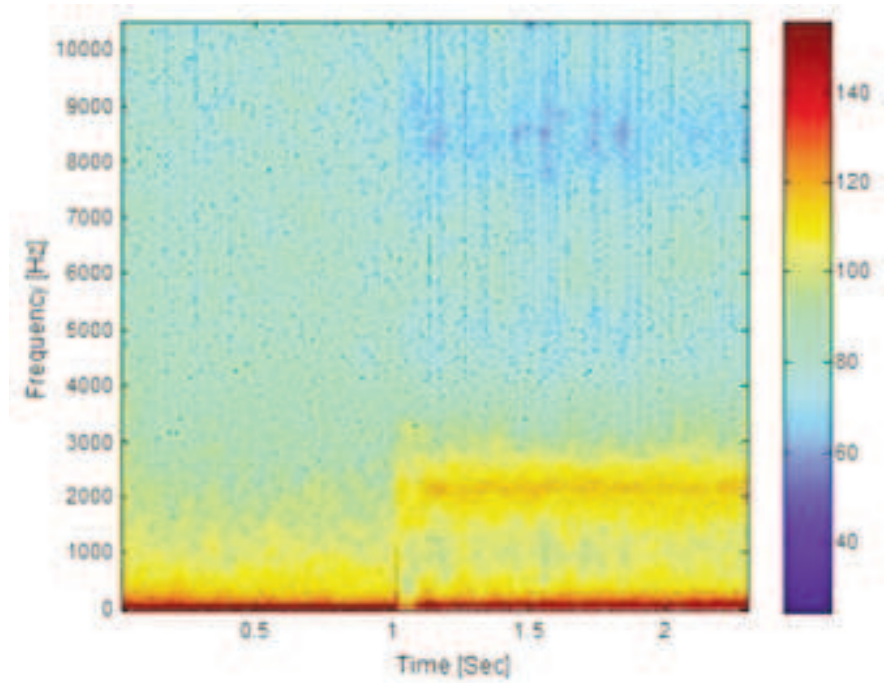

Figure 9: Voltage spectrum of the $\mathbf{R}$ phase ground short-circuit failure

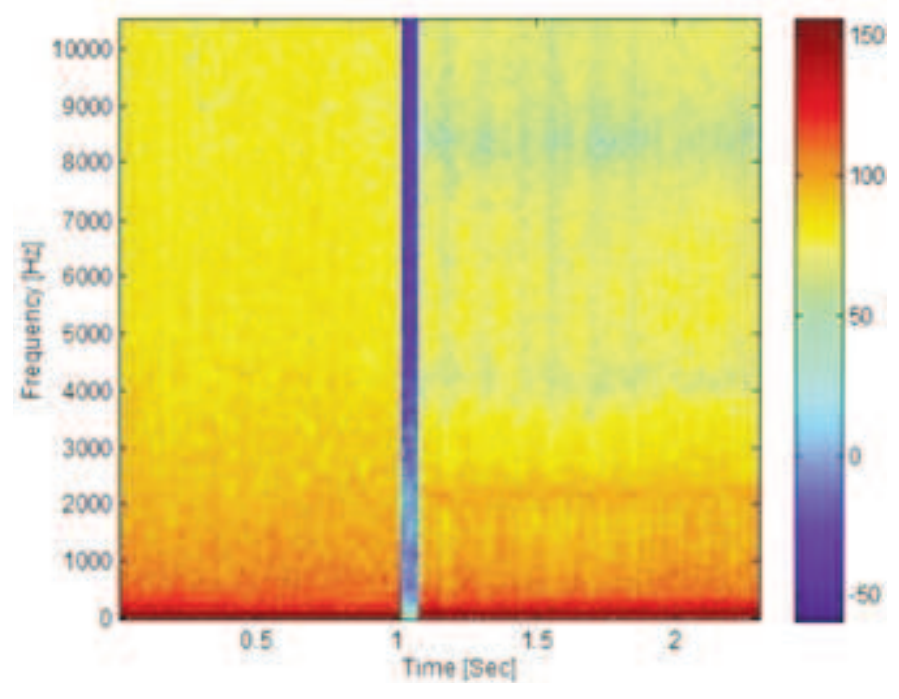

Figure 11: $1^{\text {st }}$ case Short circuit analysis of the $R$ phase at the $2^{\text {nd }}$ point

regions. A similar case can be seen in Figures 11 and 12 .

In Figure 13, the time frequency spectrum of a three phase short circuit on the $2^{\text {nd }}$ point was given. As seen on the spectrum, voltage is not induced on the system at the moment when the short circuit fault occurs, and the system returns to its nominal values as soon as the fault ends.

While a similar problem is encountered on the system, especially in the case of short circuit faults between two transmission lines, it can be seen at the $1^{\text {st }}$ measurement point that the current draws on the system in cases of fault. This can be interpreted as the system feeding other loads. The Keban power transmission line was examined exclusively in this study, and the interpretations on system characteristics are made based on this system. The results of time-frequency analyses may be different in different systems.

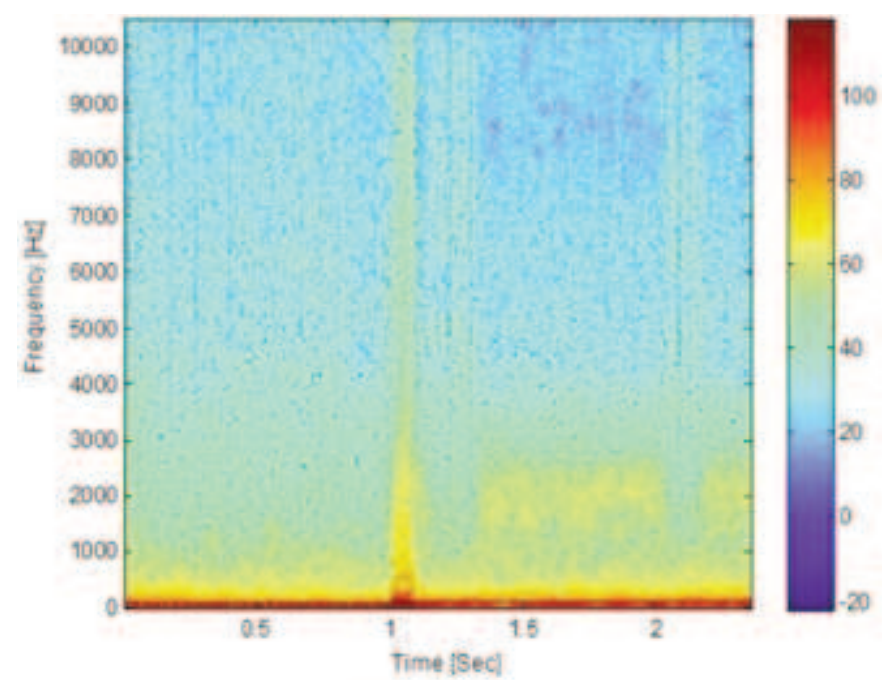

Figure 10: Short circuit analysis of the $R$ phase for Case 2

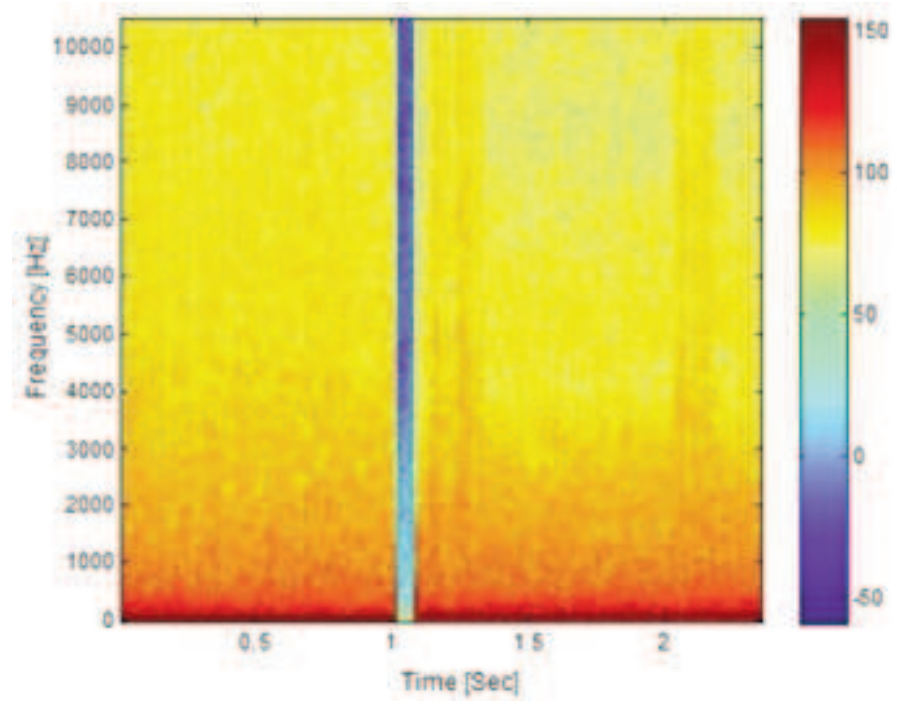

Figure 12: Time-frequency analysis of Case $2-2^{\text {nd }}$ fault point

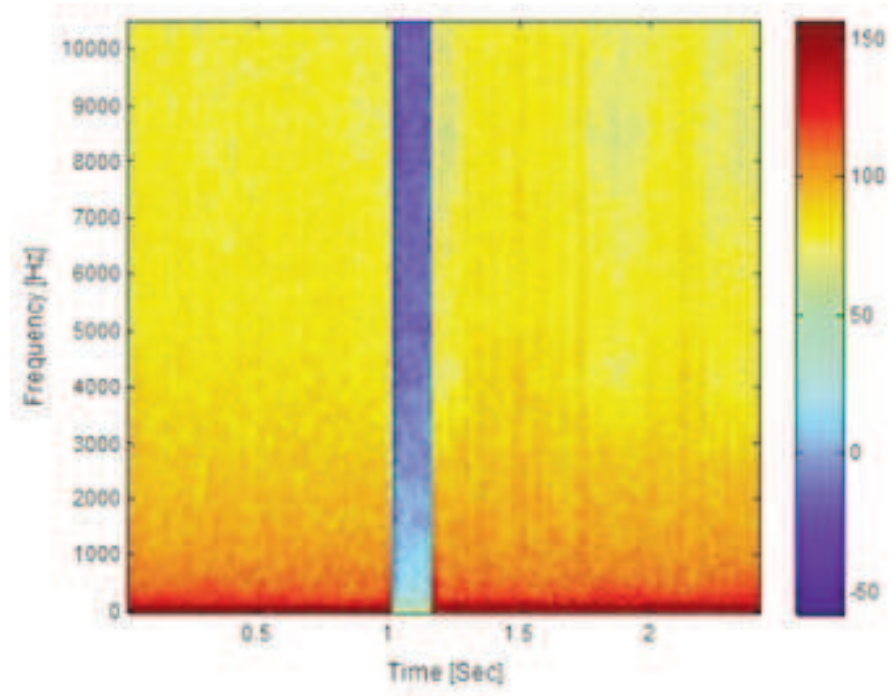

Figure 13: Time-frequency analysis of the Case $5-2^{\text {nd }}$ point 

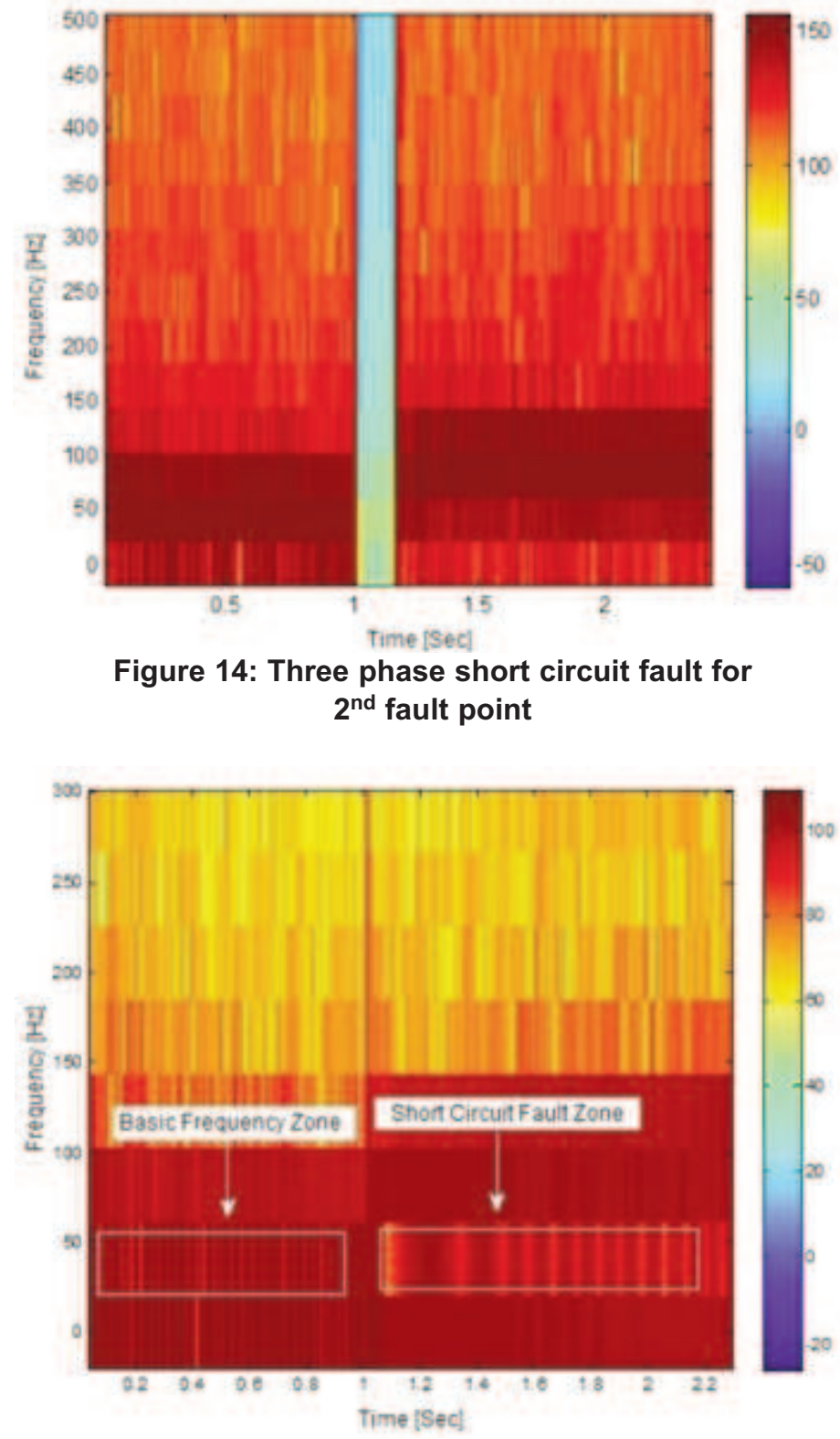

Figure 15: Analysis of short-circuit fault zones

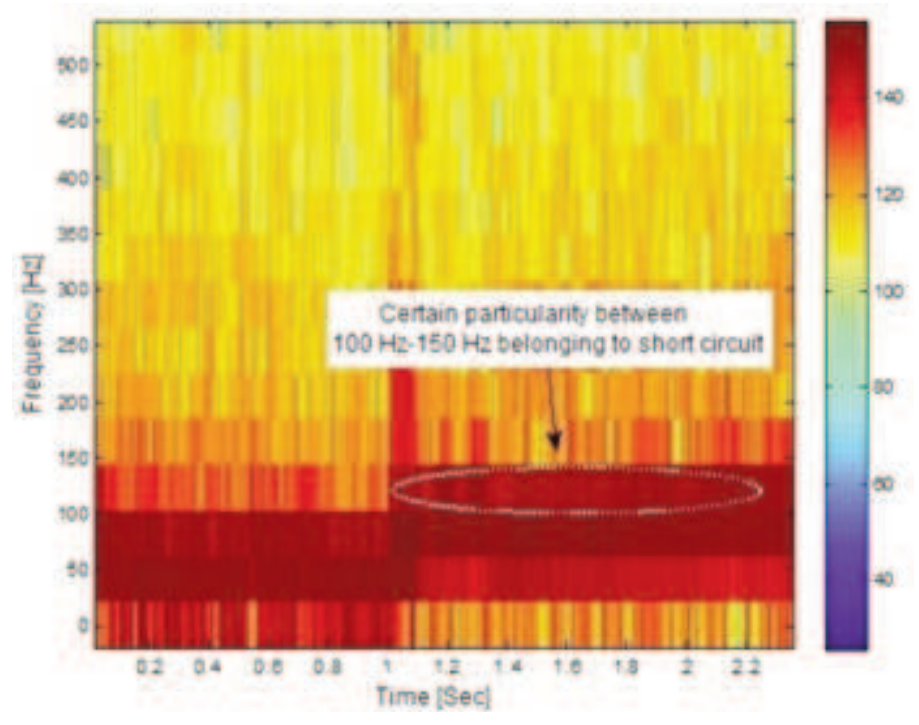

Figure 16: Short-circuit faults feature extraction

\section{Conclusion}

In this study, a line on the Keban power transmission line in the Eastern Anatolia Region in Turkey was modelled using real parameters, and the short circuit scenarios were generated over this model. In addition, the data was analysed using the Time-frequency spectrum. It was observed that the findings were consistent with the graphics derived from the Matlab-Simulink modelling. In the study, a short circuit fault was generated on one point over the line and the measurements were taken from two points. The important findings related to the measurements of the short circuit fault spectrums are listed below.

The graphic regarding the three phase short circuit fault, namely the fifth condition on the second fault point, is presented in Figure 14. This graphic can also be interpreted as a graphic demonstrating that there was no voltage transmission during the short circuit between the 1.0 and 1.3 seconds. A column can be observed at approximately $0 \mathrm{~Hz}$, which can also be seen in the colour bar between the 1.0 and 1.3 seconds.

Another important finding of this study was that $50 \mathrm{~Hz}$, which can be seen in Figure 15, is clearly the fundamental frequency area. The short circuit fault area, which is the fundamental frequency area, can be clearly observed in the same frequency area with different distributions after the short circuit. In addition, the short circuit fault area can also be seen clearly between the frequencies of $100 \mathrm{~Hz}$ and 150 $\mathrm{Hz}$ with its high amplitude.

In Figure 16, it can be observed that frequency components higher than the fundamental frequency of $50 \mathrm{~Hz}$ are formed immediately after the short circuit fault. This analysis can be regarded as one of the most important findings of the current study. The high frequency area became evident on all frequencies $(50-500 \mathrm{~Hz})$, particularly during the period between the 1.0 and 1.3 seconds. Its distinct characteristics were observed on different frequency components after the mentioned period.

Finally, another important finding of the present study was that the results of the Fourier analysis, which occur during short circuits, differ according to the type of fault, the length of the line or loading (Onal and Dikun, 2013; Seker and Akinci, 2012). In case of conducting characteristic investigations on the line, it can be suggested that the TimeFrequency analysis yields effective results and is an efficient method for determining the characteristics of a system. Regarding the region, where the present study was conducted, it was observed that the high frequencies occurred as a result of the fault in $100-150 \mathrm{~Hz}$ frequency components after the short circuit fault and that frequencies above $500 \mathrm{~Hz}$ occurred during the fault.

Further studies can investigate the sensitivity of systems to short circuit fault by using the methods of artificial intelligence. 


\section{Abbreviations}

$Z_{\text {SC }}$ Short circuit impedance

ISC Short circuit current

$\Sigma \mathrm{R}$ Sum of serial resistances

$\Sigma \mathrm{X}$ Sum of serial reactance

$\mathrm{V}_{\mathrm{n}}$ Uncharged nominal network voltage

$\mathrm{V}_{\mathrm{LL}}$ Voltage between phases

\section{References}

Acar O. (2008). Modelling on Computer Environment of Adapazarı Tedaş Ada Transformer-stadium Dispatching System. Master's Thesis, Sakarya University, Sakarya, Turkey.

Akinci T.C., Ekren N., Seker S., and Yildirim S. (2013). Continuous Wavelet Transform for Ferroresonance Phenomena in Electric Power Systems, International Journal of Electrical Power \& Energy SystemsElsevier, 44:403-409.

Akinci, T.C., Seker S., and Ekren N. (2009). Feature Extraction for Ferroresonance Phenomena in Electric Power System, International Conference on Modeling and Simulation (IASTED) MS'09, Alberta, Canada, July 2009.

Aygen Z.E., Batman M.A., and Tarkan N. (1995). Short Circuit Analysis up to Probability with Monte Carlo Method in Electrical Energy Systems. Electrical Engineering $6^{\text {th }}$ International Congress, pp.41-44, September 11-17, 1995.

Billinton R, Salvaderi L, McCalley JD, Chao H, Seitz Th, Allan R. N, Odom J, and Fallon C, (1997).

Reliability issues in today's electric power utility environment. IEEE Transac Power Systems, 124: No. 4.

Chanda R.S., and Bhattacharjee P.K. (1994). Application of computer software in transmission expansion planning using variable load structure. Electric Power Syst Res, 31:13-20.

Dogruer V. (2007). Short Circuit Fault Analysis via Matlab Simulink and Van's Energy Transmission Line Examination as a Pattern. Master's Thesis, Yuzuncu Yil University, Van, Turkey.

Donmez F. (2008). Computer Supported Analysis of System Fall Appearing after Calamity in Electrical Meshwork. Master's Thesis, Marmara University, Istanbul, Turkey.

Ekici S., Yildirim S., and Poyraz M, A. (2009). Pattern Recognition Application to Keep Distance. Gazi University Faculty of Engineering Architecture Periodical, 24:51-61.

Ekiz A., and Tumay M. Modelling Harmonics Appearing in Factories by being used Matlab/Simulink. Electrical- Electronics- Computer Engineering 10 ${ }^{\text {th }}$ International Congress, Ankara, pp.99-102.

EMO (2007). Aegean Region Production Transmission and Dispatching. Technics, EMO Izmir city Branch Energy Commision, May, 2007.

Evrenosoglu C.Y., and Abur A. (2005). Travelling Wave Based Fault Location for Teed Circuits, IEEE Transac Power Deliv, 20:1115-1121.

Faig J., Melendez J, Herraiz S, and Sánchez J. (2010). Analysis of Faults in Power Distribution Systems With Distributed Generation. International
Conference on Renewable Energies and Power Quality (ICREPQ'10), Granada, Spain, 23th to 25th March, 2010.

Gopalakrishnan A., Kezunovic M., McKenna S.M., and Hamai D.M. (2000). Fault Location Using the Distributed Parameter Transmission Line Model. IEEE Transac Power Deliv, 15:1169-1174.

Hambley, A.R. Electrical engineering: principles and applications. Prentice Hall. pp. 637, ISBN 9780131470460, Retrieved 20 April 2011.

IAEA (1995). Expansion Planning for Electrical Generating Systems, A Guidebook, Technical Reports Series No. 2411984 or User's Manual of WASP-III Plus, Computer Manual Series, No. 8, 1995.

Kamkaratug P. (2011). Redution of Over Line Current in Power System from Short Circuit Effect Using Static Synchronous Series Compensator. Am J Appl Sci, 8:129-133.

Kasikci I. (2002). Short Circuits in Power Systems: A Practical Guide to IEC 60 909. Wiley-VCH, Weinheim, Germany.

Maslo K., and Vnoucek S. (2001). Short Circuit Calculation Analysis. Paper accepted for presentation at PPT 2001, IEEE Porto Power Tech Conference 10th -13th September, Porto, Portugal, 2001.

Miroshnik R. (2000). The probabilistic model of the dynamic of the cables under short-circuit current. Comp Meths Appl Mech Eng, 187:201-211.

Onal E., and Dikun J. (2013). Short-Time Fourier Transform for Different Impulse Measurements, Balkan Journal of Electrical \& Computer Engineering, Vol.1, No.1, pp.44-47.

Pamuk N. (2011). Modelling and analysing of electrical transmission meshwork in Sakarya by being used matlab/simulink programs. Erciyes University Science Institute Periodical, 27:19-39.

Paska J. (2007). Methodologies and Tools for Electric Power System Reliability Assessment on HL I and HL II Levels, 9th International Conference-Electrical power Quality and Utilisation, Barcelona, October 9-11, 2007.

Patel R., Bhatti T.S., and Kothari D.P. (2002). MATLAB/Simulink-based transient stability analysis of a multimachine power system. Int J Electrical Eng Educ, 39:320-336.

PDH Online. Introduction to Short Circuits Analysis. www.pdhonline.org/cgi-in/quiz/courses/courselist. cgi?class_name $=e 204$ :Introduction, 18/03/2013.

Schneider Electric (2005). Calculation of Short-Circuit Currents. Cahier Technique No.158.

Seker S., Akinci T.C., and Taskin S. (2012). Spectral and Statistical Analysis for Ferroresonance Phenomenon in Electric Power System, Electrical EngineeringSpringer 2012, Vol..94, No..2, pp.117-124.

Serrican A.C., Ozdemir A, and Kaypmaz A. (2010). Short circuit analyzes of power system of PETKIM petrochemical aliaga complex. Online J Electron Elec Eng (OJEEE), 336-340.

Smeets R.P.P. (2010). Lathouwers AGA. Short-circuit withstand of T\&D components, CEPSI Proceedings of the 18th Conference on the Electronic Power 
Supply Industry, Taipei, Taiwan, October 24-28, 2010.

TEIAS: Transmission and Dispatching System-

Transmission System. http://www.teias.gov.tr/apkuretim/iletimdagitim.htm. 08/04/2011.

TEIAS: Turkey Electricity Production- Dispatching Statistics 2008,

http://www.teias.gov.tr/istatistik2008/index.htm. 08/04/2011.

TEIAS: Load Dispatch Chamber Headship Management Function Reports. http://www.teias.gov.tr/yukdagitim/yillik_menu.htm. 08/04/2011.

TEIAS: $9^{\text {th }}$ Dispatching Facility and Management Group Directorship $380 \mathrm{Kv}$-ENH List. www. teias.gov.tr/Gr9/eihatlariliste.xls. 08/04/2011.

TEIAS: Load Dispatch Management Headship. http://www.teias.gov.tr/haritayukOK.htm. 09.04.2011.

Tekin K. (2006). Short Circuit and Interaction Examination in Electrical Systems Containing Wind Energy Facility. Master's Thesis, Istanbul Technical University, Istanbul, Turkey.

Unal A. (1996). Determination of mathematical model of an electric power system using linear graph. Math Comput Appl, 1:134-139.

Vaseghi V.S. (1996). Advanced Signal Processing and Digital Noise Reduction, John Wiley, New York, USA.

Yuhai S., Guangjian W., and Xiangguo C. (2007). Fault Detection and Analysis of Distributed Power System Short-circuit Using Wavelet Fractal Network, The Eighth International Conference on Electronic Measurement and Instruments.

Závodný I.M (2005). Power Electric System Transient Simulation Using Matlab-Simulink. Konference a soutež Student EEICT.

Received 30 October 2013; revised 17 March 2015 